\title{
Determinants and Distribution of Comprehensive HIV/AIDS Knowledge in Ghana
}

\author{
Ama P. Fenny ${ }^{1}$, Aba O. Crentsil ${ }^{2} \&$ Derek Asuman ${ }^{1}$ \\ ${ }^{1}$ Economics Division, Institute of Statistical, Social and Economic Research (ISSER), University of Ghana, Accra, \\ Ghana \\ ${ }^{2}$ Social Division, Institute of Statistical, Social and Economic Research (ISSER), University of Ghana, Accra, \\ Ghana \\ Correspondence: Ama Pokuaa Fenny, Economics Division, Institute of Statistical, Social and Economic Research \\ (ISSER), University of Ghana, P.O. Box LG 74, Accra, Ghana. Telephone: 233-2433-43855; 233-261-563-405. \\ E-mail: amafenny@yahoo.co.uk; apfenny@ug.edu.gh
}

Received: August 23, 2017 Accepted: September 27, 2017 Online Published: October 9, 2017

doi:10.5539/gjhs.v9n12p32 URL: https://doi.org/10.5539/gjhs.v9n12p32

\begin{abstract}
Globally, nearly 37 million people are living with HIV with about 70 percent of these living in Sub-Saharan Africa (SSA). Stigma and discrimination remain one of the major barriers to preventing new infections in the country. However, misconceptions about HIV/AIDS have been indicated as one of the key drivers of the disease. Efforts to prevent new infections have not been entirely successful. Therefore, this study aims to examine the trends and distribution in comprehensive knowledge of HIV and AIDS and determine the factors associated with comprehensive awareness of HIV and AIDS among adult women and men. The study relies on data from three rounds of Ghana Demographic \& Health Surveys conducted in 2003, 2008 and 2014 to show trends. Logistic regression was used for multivariate analysis. The thematic mapping of HI/AIDS comprehensive knowledge was conducted using ArcGIS version 10.4 using GPS coordinates in the 2014 GDHS which contained aggregated individual characteristics and HIV knowledge scores.

While comprehensive HIV and AIDS knowledge is above $50 \%$ among adult population in Ghana, the results show a significant decrease in comprehensive knowledge from $72 \%$ in 2008 to $59 \%$ in 2013 . The strongest predictors for having comprehensive knowledge were found to be education; gender, marital status, locality, occupation and wealth status. The paper demonstrates that preventive activities leading to improvement in the comprehensive knowledge of HIV and AIDS in Ghana is needed. Sound knowledge about HIV and AIDS is critical for the adoption of behaviours that reduce the risk of HIV transmission. Education on HIV prevention must be expanded to improve the comprehensive knowledge of the disease.
\end{abstract}

Keywords: HIV/AIDS, comprehensive knowledge, thematic mapping, Ghana

\section{Introduction}

One of the major targets of the Millennium Development Goal Six was halting and reversing the HIV epidemic by 2015. Progress on this target is measured by a range of factors, including HIV rates among young people aged 15 to 24, rates of condom use and knowledge of HIV and AIDS. The global response to HIV has averted 30 million new HIV infections and nearly 8 million (7.8 million) AIDS-related deaths since 2000, when the MDGs were set (MDG Report, 2015). However, shortfalls remain and the global plan is to move towards the elimination of new HIV infections among children and keeping their mothers alive. Knowledge and behaviour affect an individual's risk of acquiring HIV infection and therefore behaviour change remains the world's primary tool for achieving this goal.

In Ghana, the HIV epidemic continues to be a generalised epidemic with a prevalence rate of 2.4 percent in 2016 , an increase of 0.6 percentage points from 2015. In 2014, when the median HIV prevalence as determined by the HIV Sentinel Surveillance Survey (HSS) was 1.6., many people were of the view that the efforts to reduce new infections were proving successful. However, there has been a steady increase since 2014, which demands a further look. Regional trends in HIV prevalence has also shifted from previous years. For instance, Volta Region and Brong Ahafo Region which previously had prevalence rates around 1 percent, have suddenly shot up to 2.7 percent in 2016 (National AIDS/STI Control Programme (NACP), 2017). A Modes of Transmission (MOT) study 
undertaken in 2014 to determine the contributions of various population groups (aged 15-49 years) to HIV transmission, estimated 6,704 new HIV infections among adults (15-49) in Ghana in 2014 with the majority of infections (72.3\%) occurring among the general low risk population. Currently, transmission among the general population (persons having casual heterosexual sex, their partners, and couples in stable heterosexual relationships) is becoming a more important driver of the HIV epidemic in Ghana (United Nations General Assembly Special Session (UNGASS), 2014).

Sound knowledge about HIV and AIDS is an essential prerequisite for adoption of behaviours that reduce the risk of HIV transmission. A key component of the National Strategic Plan is the prevention of new HIV infections. The plan sets the targets for prevention strategies and outputs to halve HIV infections by year 2015 relative 2010 baseline figure of about 25,000. This will be achieved if non-clinical HIV prevention interventions such as Behavior Change Communication (BCC) and Awareness Campaigns are effectively implemented. In order to design appropriate HIV prevention programs, it is important to examine the perception and knowledge of HIV and AIDS and methods of prevention. The objective of this study is to examine comprehensive knowledge of HIV and AIDS and the factors associated with comprehensive awareness of HIV/AIDS among adult people in Ghana. A review of programs on the awareness of HIV and AIDS among the general adult population remains limited in Ghana. Interventions are needed to build knowledge of HIV and AIDS transmission and prevention methods through mass media campaigns, and information, education and communication programs (IEC) on HIV and AIDS.

Intervention programs presuppose that health related behaviour is determined by individuals' perceptions of their proneness to infections, the benefits they derive from behaviour change and the constraints they face to change (Adedimeji, 2005). Others argue that behavioural change goes beyond the individual perception to a much broader engagement within the social, cultural, political and economic contexts (Sweat \& Denison, 1995). This means that merely providing basic awareness of HIV and AIDS may not provide enough information to prevent the spread of the infection. Additional communication processes may be needed in order to promote behavioural change (Brown, Macintyre, \& Trujilo, 2003). The underlying motivation of many HIV and AIDS awareness campaigns is the fact that the possession of adequate and correct knowledge will drive preventive efforts (Odu \& Akanle, 2008). For instance, the belief that a healthy-looking person cannot be infected with HIV is a common misconception that can result in unprotected sexual intercourse with otherwise infected partners. This precludes that rejecting major misconceptions about modes of HIV transmission is as important as correct knowledge of true modes of transmission.

In Ghana, the general awareness of HIV and AIDS is high with about 98 percent of all respondents having heard of HIV/AIDS (Ghana Statistical Service (GSS), 2014). However, many Ghanaian adults lack accurate knowledge about the ways through which HIV can and cannot be transmitted. Only $18 \%$ of women and $30 \%$ of men have comprehensive knowledge about HIV/AIDS. Comprehensive knowledge on HIV and AIDS is important in the adoption of behaviour that reduces the risk of HIV transmission. Studies have shown varying levels of comprehensive knowledge about HIV and AIDS across the continent but the across 23 countries show that countries in West Africa had the lowest levels of comprehensive knowledge compared with East Africa and southern Africa (Mishra et al., 2009; Wang, Alva, \& Wang, 2012). Other specific country-level studies find low levels of comprehensive knowledge. For instance, among slums in India (Jha et al., 2015), among urban young women in Kenya (Ochako et al, 2008) and among in-school adolescents in Ethiopia (Oljira, Yemane \& Alemayehu, 2013). This shows that a huge knowledge gap needs to be addressed. Some examples of common misconceptions include: a person can get HIV from a mosquito bite, by sharing food with someone who is infected, by hugging or shaking hands with an infected person or through supernatural means.

The aim of this study is to examine trends in comprehensive knowledge of HIV and AIDS and determine the factors associated with comprehensive awareness of HIV and AIDS among adult women and men in Ghana. Two general questions are raised in this study. First, what are the distributions of comprehensive knowledge of HIV and AIDS among adults in Ghana and then what factors determine comprehensive knowledge of HIV and AIDS among adults in Ghana?

\section{Data and Methods}

\subsection{Source of Data}

This study uses data from 2003, 2008 and 2014 Ghana Demographic \& Health Surveys to provide the trend in comprehensive HIV and AIDS knowledge among adult population (GSS, 2003; 2008; 2014). The GDHS are nationally representative surveys of women aged 15-49 years. Bivariate and multivariate analysis are based on the latest available data, GDHS 2014, to provide a clear indication on the most recent determinants of HIV and AIDS 
comprehensive knowledge among adults in Ghana. The 2014 Ghana Demographic and Health Survey (GDHS), a nationally representative survey of 9,396 women age 15-49 and 4,388 men age 15-59 from 11,835 interviewed households. The primary purpose of the GDHS 2014 is to provide information on fertility, family planning, infant and child mortality, maternal and child health, and nutrition. The survey also collects information on malaria treatment, prevention, and prevalence among children age 6-59 months; blood pressure among adults; anaemia among women and children; and HIV prevalence among adults. The survey was conducted by the Ghana Statistical Service (GSS), the Ghana Health Service (GHS), and the National Public Health Reference Laboratory (NPHRL) of the GHS.

\subsection{Study Variables}

The outcome variable in this study is comprehensive knowledge of HIV and AIDS measured by correct answers to HIV transmission modes and HIV prevention methods. A respondent is considered to have comprehensive knowledge of HIV and AIDS prevention methods if s/he responded positively (yes) to Questions $1-3$ and responded negatively (No) to question number 4 as below. The questions asked were: 1) a healthy looking person can have HIV, 2) HIV cannot be transmitted by supernatural means, 3) a person cannot contract HIV by sharing food with a person who has HIV and 4) HIV can be transmitted through mosquito bites. An index of comprehensive knowledge is created based on the number of correct responses. The index has three categories of responses - inadequate, average and comprehensive knowledge. The classification of responses into these three categories are deemed appropriate due to the wide variations in the responses to the questions.

As considered in similar studies in Ethiopia, Kenya and India the independent variables will include socio-demographic and economic characteristics such as age, education, marital status, occupation, media exposure, prior HIV testing and wealth index. Behavioral attitudes are captured by frequency of listening to radio (media exposure). Also included will be accepting attitudes toward People Living with HIV/AIDS (PLHIV). In the DHS surveys, respondents were asked about four aspects of acceptance of people with HIV: whether they would want to keep it secret that a family member had HIV; whether they would be willing to care for a family member or relative with HIV; whether they believed that a female teacher (some surveys did not specify the gender of the teacher) living with HIV should be allowed to continue teaching; and whether they would buy fresh vegetables from a vendor who had HIV. Despite the gains made by the national response, HIV and AIDS-related stigma and discrimination is still a pervasive problem, and PLHIV in Ghana, as elsewhere, face stigma and discrimination in a variety (Note 1). It will therefore be important to test if these variables are correlates to comprehensive knowledge of HIV and AIDS.

\subsection{Methods of Analysis}

Descriptive statistics and time (year of survey) were used to achieve the show trends in comprehensive knowledge. Bivariate and multivariate logistic regression was used to identify the main correlates of comprehensive HIV and AIDS knowledge. Explanatory variables were included in the multivariate model.

\subsubsection{Regression Models}

The multinomial logistic model is applied in the estimating the predictors of comprehensive HIV/AIDS knowledge in Ghana. This is because the multinomial logistic model is based on the maximum likelihood estimation to evaluate the probability of categorical membership. The multinomial logistic model allows for more than two categories of the dependent variable to be estimated. Comprehensive HIV/AIDS knowledge has been defined to include three sets of alternatives hence the use of the multinomial logistic model in comparing the various alternatives.

The multinomial logistic model can be stated as:

$$
P_{i j}=\frac{\exp \left(X_{i}^{\prime} \beta_{j}\right)}{\sum_{i=1}^{m} \exp \left(X_{i}^{\prime} \beta_{j}\right)}, \mathrm{j}=1, \ldots, \mathrm{m}
$$

where $P_{i j}$ is the predicted probability of categorical membership, $X_{i}$ is a set of explanatory variables, and $\beta_{j}$ are the estimated coefficients, including an intercept term. The multinomial logit model ensures that $0 \leq P_{i j} \leq 1$ and $\sum_{i=1}^{m} P_{i j}=1$. To ensure model identification, is set to zero for one category of responses, and coefficients are interpreted with respect to that category, called the base outcome. Multinomial logit is based on an assumption of independence among choices made on dependent variable. The assumption states that the choice of one category is not related to the choice of membership in another category. To address this, the study uses the Hausman IIA to test 
for the assumption of independence among dependent variable choices (Hausman \& McFadden, 1984). The study presents the marginal effects of the multinomial logit regression. The statistical software STATA version 14 was used for analysis.

\subsection{Spatial Analysis}

The Mapping analyses were conducted using ArcGIS version 10.4 (ESRI, Redlands, CA, USA). The Regional boundaries and administrative units were obtained from DIVA-GIS Free Spatial Data (Note 2). These data were originally obtained from Global Administrative Areas (GADM) and the Defense Mapping Agency (DMA) Digital Chart of the World, Fairfax, Virginia, 1992 (Note 3). The study relied on GPS coordinates in the 2014 GDHS which contained aggregated individual characteristics and HIV knowledge scores from each Enumeration Area (EA). These were joined to the EA layer polygon shape file. Records were joined based on each EAs unique identification code to create thematic maps. The data were classified by the natural breaks method, which identifies the partitions capable of achieving the minimum difference between the specimens in the same segment and the maximum difference between specimens in the various segments (Bivand, Pebesma \& Gómez-Rubio (2008).

\section{Results}

\subsection{Sample Description}

Table 1 shows the description of 10,956 adults aged 15-49, interviewed in the GDHS 2014 survey.

The sample consisted of $67 \%$ female, $55 \%$ currently married and almost evenly distributed across the five household wealth categories. However, $22 \%$ of the total were in the poorest wealth quintile. Majority had secondary education or above (65\%) with most them in some form of employment (78\%). With regard to media exposure, about $60 \%$ of them had listened to the radio at least once a week prior to study.

Table 1. Distribution of adults, 15-49 years, GDHS 2014

\begin{tabular}{ll}
\hline Variable & Mean \\
\hline Gender & 0.328 \\
Male & 0.672 \\
Female & 30.232 \\
Age of respondents & \\
Marital status of respondents & 0.372 \\
Never married & 0.549 \\
Currently married/consensual union & 0.079 \\
Previously married/consensual union & \\
Location of residence & 0.503 \\
Urban & 0.497 \\
Rural & \\
Educational Attainment of Respondent & 0.176 \\
No Education & 0.170 \\
Basic Education & 0.577 \\
Secondary Education & 0.077 \\
Tertiary Education & \\
Media Exposure (Frequency of listening to radio) & \\
Not at all & 0.124 \\
Less than once a week & 0.274 \\
At least once a week & 0.602 \\
Occupation of respondent & \\
\hline
\end{tabular}




$\begin{array}{lc}\text { Unemployed } & 0.222 \\ \text { Professional/Technical/Managerial/Clerical } & 0.086 \\ \text { Services/Sales } & 0.265 \\ \text { Agriculture } & 0.262 \\ \text { Manual - Skilled / Unskilled } & 0.165 \\ \text { Household Wealth Index } & 0.223 \\ \text { Poorest } & 0.191 \\ \text { Poorer } & 0.202 \\ \text { Middle } & 0.199 \\ \text { Richer } & 0.186 \\ \text { Richest } & 10,956 \\ \text { Observations } & \end{array}$

Based on correct answers to questions testing respondents' knowledge on HIV/AIDS transmission, an index of knowledge is constructed using the principal component analysis technique. A summary statistics of the index of comprehensive knowledge is presented in Table 2. About a third, $31 \%$ of the respondents had comprehensive HIV and AIDS knowledge while $34 \%$ had inadequate knowledge of HIV and AIDS knowledge. Broken down into the individual questions, $53 \%$ of the sample believed that HIV and AIDS was caused by witcheraft or supernatural means. Majority of them believed that a health person could have HIV and AIDS (85\%) and $71 \%$ were positive that HIV and AIDS was not transmitted by sharing food with others. However, $36 \%$ of them believed that mosquito bites caused HIV and AIDS. Stigma and discrimination is still rampant as $66 \%$ would not buy fresh vegetables from PLWHA and 54\% will keep their positive status from family and friends (Table 3 ).

Table 2. Comprehensive Knowledge of HIV and AIDS, 15-49 years, GDHS 2014

\begin{tabular}{ll}
\hline Index of Comprehensive Knowledge & Mean \\
\hline Inadequate Knowledge & 0.338 \\
Average Knowledge & 0.352 \\
Comprehensive Knowledge & 0.310 \\
Observations & 10,956 \\
\hline
\end{tabular}

Table 3. Beliefs or perceptions reflecting knowledge of HIV and AIDS, 15-49 years, GDHS 2014

\begin{tabular}{lc}
\hline Variable & Mean \\
\hline HIV/AIDS caused by witchcraft/supernatural means & 0.535 \\
Yes & 0.465 \\
No & 0.359 \\
Can HIV/AIDS be caused by mosquito bites & 0.641 \\
Yes & 0.283 \\
No & 0.717 \\
Can HIV/AIDS be caused by sharing food with PLWHA & 0.847 \\
Yes & 0.153 \\
No & \\
Healthy person can have HIV & \\
Yes & \\
No & \\
\hline
\end{tabular}


Keep it secret if family member had HIV

No

Yes

0.541

Allow teacher with HIV to continue teaching

No

Yes

Willing to care for family member with HIV

No

0.378

Yes

0.602

Buy fresh vegetables from vendor with HIV

No

Yes

0.343

Observations

10,956

\section{Results for Spatial Analysis}

The spatial distribution of HIV knowledge in Ghana is illustrated in Figure 1 -Figure 3. These figures show the presence of spatial variations of HIV knowledge which is useful to existing HIV prevention programs. HIV knowledge score is highest in the red coloured regions and lowest in the green coloured regions as seen in the Knowledge maps. 


\section{Legend}

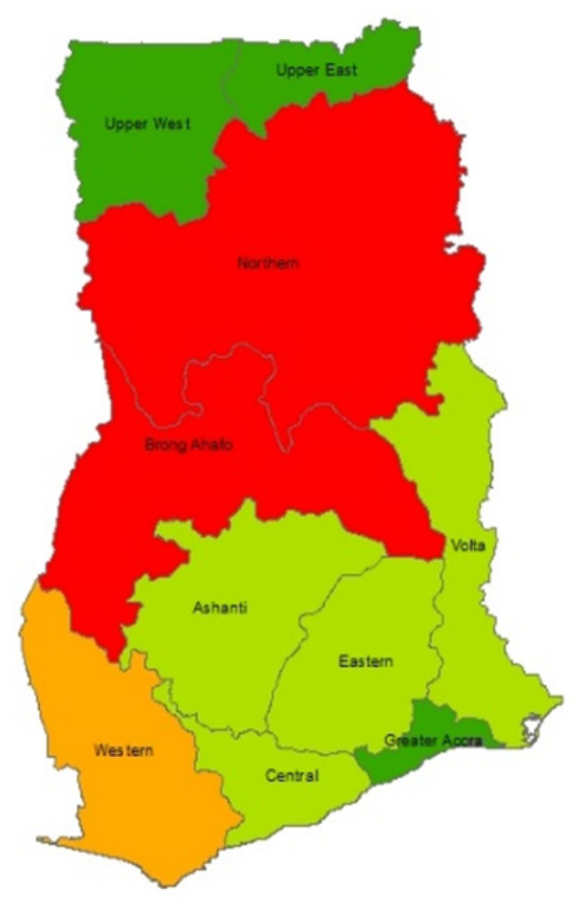

Low HIV knowledge Score

$5.5 \%-7.4 \%$

ए.5\%-10.6\%

$10.7 \%-11.3 \%$

$11.4 \%-14.6 \%$

$\begin{array}{lllll}0 & 3570 & 140 & 210 & 280\end{array}$

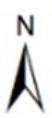

Figure 1. Low HIV knowledge Score 


\section{Legend}

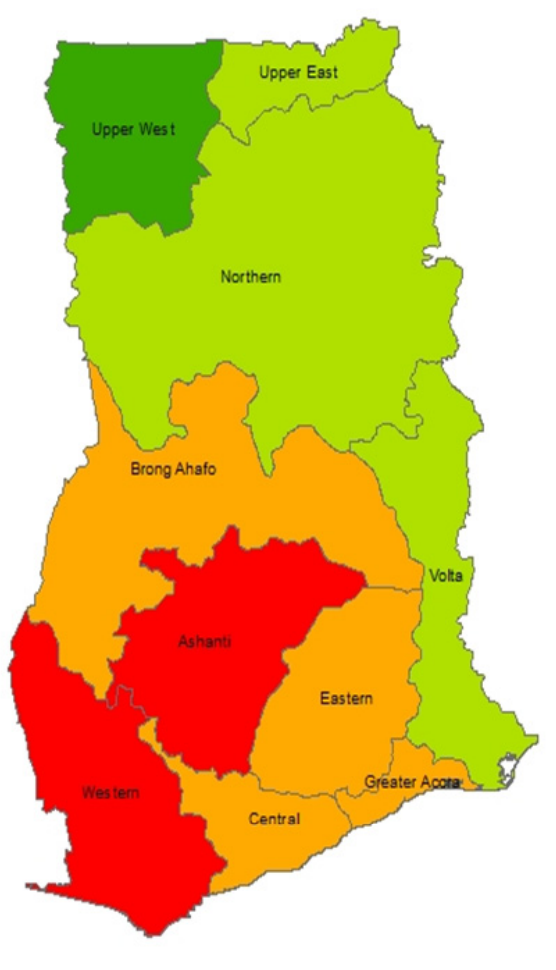

Medium HIV knowlegde score

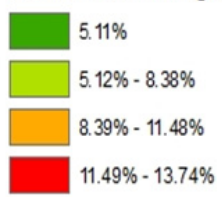

Kilometers

$\begin{array}{lllll}0 & 3570 & 140 & 210 & 280\end{array}$

$N$

Figure 2. Medium HIV Knowledge Score 


\section{Legend}

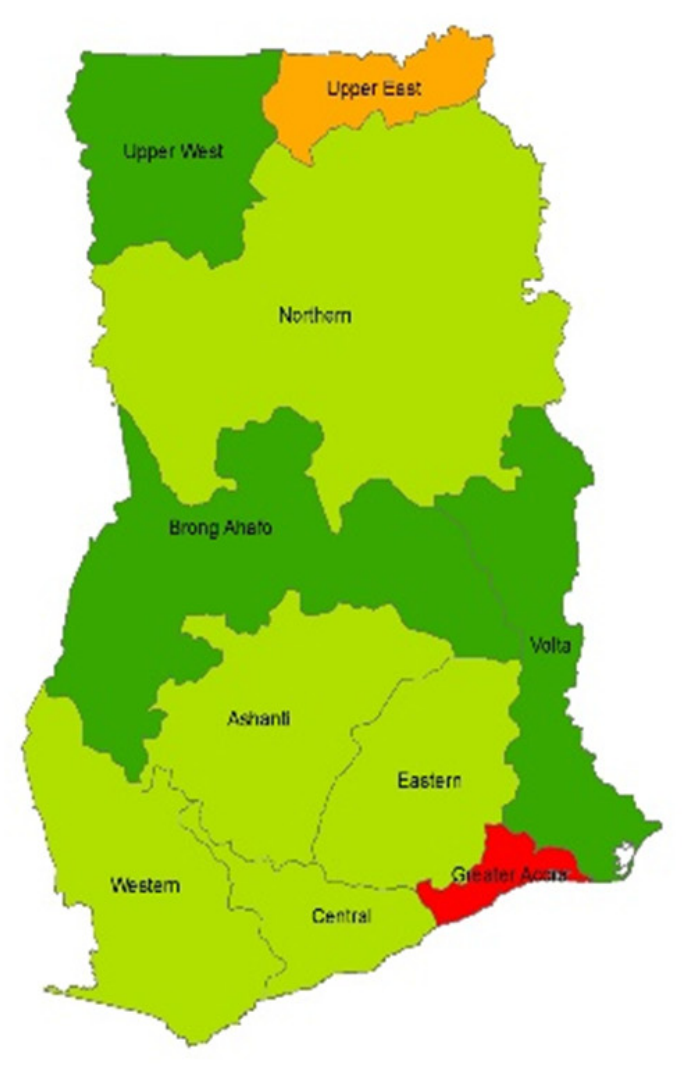

Comprehensive HIV Knowledge Score

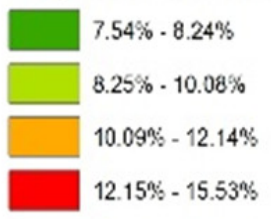

Kilometers

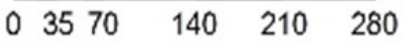

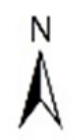

Figure 3. Comprehensive HIV Knowledge

Figure 1 shows the overall distribution of low knowledge of HIV as estimated by the 2003, 2008 and 2014 Ghana Demographic \& Health Surveys. The knowledge scores ranges from 5.5\%-14.6\% with the highest scores seen in the Northern and Brong Ahafo Regions. Figure 2 shows that medium knowledge of HIV in the respondent ranges from $5.11 \%-13.74 \%$ with the highest rates reported in the Ashanti and Western Regions. Figure 3 shows the distribution of comprehension knowledge of HIV across the country. High comprehensive knowledge of HIV was observed in the Greater Accra Region, which is the capital region of Ghana. Low comprehensive knowledge of HIV was observed Volta, Brong Ahafo and Upper West Regions. 


\subsection{Multivariate Analysis}

Table 4 presents multivariate analysis results of comprehensive HIV and AIDS knowledge among adults aged 15-49 in Ghana. The coefficients of the multinomial logit model do not indicate the effect of a change in a regressor on the probability of a respondent belonging to a category of the outcome. For this reason, we present the Average Marginal Effects of the multinomial logit model which shows how a change in a regressor effects the probability of a respondent belonging to a category of the outcome.

Table 4. Average Marginal Effects of the Multinomial Logit Regression Estimating Comprehensive HIV/AIDS Knowledge

\begin{tabular}{|c|c|c|c|}
\hline Explanatory Variable & Inadequate & Average & Comprehensive \\
\hline \multirow[t]{2}{*}{ Female } & $0.0250 * * *$ & $0.0440 * * *$ & $-0.0690 * * *$ \\
\hline & $(0.0104)$ & $(0.0111)$ & $(0.0102)$ \\
\hline \multirow[t]{2}{*}{ Age } & 0.0008 & -0.0001 & -0.0007 \\
\hline & $(0.0006)$ & $(0.0006)$ & $(0.0006)$ \\
\hline \multirow[t]{2}{*}{ Rural } & $0.0236^{* *}$ & 0.0092 & $-0.0329 * * *$ \\
\hline & $(0.0111)$ & $(0.0122)$ & $(0.0109)$ \\
\hline \multicolumn{4}{|l|}{ Marital Status } \\
\hline \multicolumn{4}{|l|}{ Never Married or in Union } \\
\hline \multirow[t]{2}{*}{ Currently Married or in Union } & $0.0248 * *$ & -0.0061 & -0.0187 \\
\hline & $(0.0127)$ & $(0.0136)$ & $(0.0121)$ \\
\hline \multirow[t]{2}{*}{ Previously Married or in Union } & $0.0742 * * *$ & -0.0124 & $-0.0618 * * *$ \\
\hline & $(0.0198)$ & $(0.0209)$ & $(0.0186)$ \\
\hline \multicolumn{4}{|l|}{ Educational Attainment } \\
\hline \multicolumn{4}{|l|}{ No Education } \\
\hline \multirow[t]{2}{*}{ Basic Education } & $-0.0318^{* *}$ & $0.0388^{* *}$ & -0.0071 \\
\hline & $(0.0159)$ & $(0.0164)$ & $(0.0152)$ \\
\hline \multirow[t]{2}{*}{ Secondary Education } & $-0.1354 * * *$ & $0.0463 * * *$ & $0.0892 * * *$ \\
\hline & $(0.0147)$ & $(0.0149)$ & $(0.0139)$ \\
\hline \multirow[t]{2}{*}{ Tertiary Education } & $-0.3020 * * *$ & 0.0095 & $0.2925^{* * *}$ \\
\hline & $(0.0239)$ & $(0.0269)$ & $(0.0267)$ \\
\hline \multicolumn{4}{|l|}{ Media Exposure } \\
\hline \multicolumn{4}{|l|}{ Not at all } \\
\hline \multirow[t]{2}{*}{ Less than once a week } & -0.0107 & 0.0054 & 0.0053 \\
\hline & $(0.0139)$ & $(0.0159)$ & $(0.0148)$ \\
\hline \multirow[t]{2}{*}{ At least once a week } & -0.0042 & -0.0059 & 0.0100 \\
\hline & $(0.0131)$ & $(0.0149)$ & $(0.0140)$ \\
\hline \multicolumn{4}{|l|}{ Occupation } \\
\hline \multicolumn{4}{|l|}{ Unemployed } \\
\hline \multirow[t]{2}{*}{ Prof./Tech./Managerial/Clerical } & -0.0321 & -0.0132 & $0.0453^{* *}$ \\
\hline & $(0.0241)$ & $(0.0228)$ & $(0.0210)$ \\
\hline \multirow[t]{2}{*}{ Services/Sales } & $0.0220^{*}$ & $0.0380 * * *$ & $-0.0600 * * *$ \\
\hline & $(0.0133)$ & $(0.0142)$ & $(0.0132)$ \\
\hline Agriculture & $0.0553^{* * *}$ & 0.0124 & $-0.0677 * * *$ \\
\hline
\end{tabular}




\begin{tabular}{llll}
\hline & $(0.0147)$ & $(0.0163)$ & $(0.0150)$ \\
Manual - Skilled /Unskilled & $0.0326^{* *}$ & 0.0176 & $-0.0502^{* * *}$ \\
& $(0.0149)$ & $(0.0160)$ & $(0.0146)$
\end{tabular}

Wealth Index

Poorest

Poorer

\subsection{3}

(0.0131)

0.0011

Middle

(0.0143)

Richer

Richest

Keep it secret if family member has HIV

Willing to care for family member with HIV

Allow teacher with HIV to teach

Buy vegetables from vendor with HIV

Number of Observations
0.0102

(0.0147)

0.0001

(0.0156)

$0.0714 * * *$

(0.0183)

$0.0530 * * *$

(0.0204)

0.0138

(0.0093)

$-0.0053$

(0.0118)

0.0068

(0.0108)

0.0161

(0.0109)

10956
$-0.0215$

(0.0140)

$-0.0012$

(0.0145)

$-0.0321 * *$

(0.0160)

0.0093

(0.0181)

$-0.0168 * *$

(0.0084)

0.0760 ***

(0.0107)

$0.1107 * * *$

(0.0098)

$0.0877 * * *$

(0.0097)

10956

Standard errors in parenthesis. $* * * \mathrm{p}<0.01 * * \mathrm{p}<0.05 * \mathrm{p}<0.1$.

The marginal effects indicate significant gender differences in comprehensive knowledge on HIV/AIDS in Ghana. Specifically, we find that females are more likely to possess inadequate and average knowledge on HIV/AIDS transmission compared to their male counterparts. On the contrary, the probability that a female will possess comprehensive is reduced compared to males. The effect of gender on comprehensive HIV/AIDS is similar to the findings of Oljira et al., (2013) in a study among in-school adolescents in eastern Ethiopia. They suggest that such gender effects on HIV/AIDS knowledge may result from cultural norms and values which may restrict females from discussing sexually related issues and encourages such discussions amongst males. This gender gap in knowledge on the correct modes of transmission of the HIV/AIDS virus requires that policies that are initiated to provide HIV/AIDS education to take into consideration the needs of women.

Similar to the gender differences in knowledge on the modes of transmission of HIV/AIDS, there exists locational effects on the determinants of comprehensive HIV/AIDS knowledge in Ghana. Compared to urban residents, rural residents are more likely to have inadequate knowledge on HIV/AIDS and less likely to possess comprehensive knowledge. The differences in the effect of the location of the household on HIV/AIDS knowledge may reflect the urban biasedness of HIV/AIDS educational campaigns in Ghana.

We further examine the relationship between current marital status of the respondents and comprehensive HIV/AIDS knowledge. The results indicate that being ever married or in a union (currently or previous) is associated with an increase probability of inadequate HIV/AIDS knowledge. These results are similar to Okacho et al., (2008) in a study among urban women in Kenya. The relationship between marital status and HIV/AIDS knowledge is confirmed by the significant negative effect of previously being married or in a union on comprehensive HIV/AIDS knowledge.

Generally, the results indicate significant relationships between the level of educational attainment and the level of awareness of HIV/AIDS transmission modes. The results reveal that compared persons with no formal education, any level of formal educational attainment is associated with a reduction in the probability of inadequate 
HIV/AIDS knowledge. Equally, attaining basic as well as secondary education exerts a positive effect on a respondent possessing average HIV/AIDS knowledge. Whilst attaining secondary and tertiary education has a significant positive relationship on comprehensive HIV/AIDS knowledge. These results may be taken as indications of the effect of mainstreaming HIV/AIDS into the formal educational curriculum. Surprisingly, we do not evidence of the effect of media exposure on comprehensive HIV/AIDS knowledge in Ghana.

We proceed to examine the relationship between occupational status and HIV/AIDS knowledge in Ghana. An essential part of the HIV/AIDS campaign in Ghana has focused on the workplace. The National Workplace HIV and AIDS policy amongst other objectives sought educate persons on the HIV/AIDS and promote healthy sexual and reproduction health among workers. The marginal effects reveal that compared to unemployed persons, employment in services/sales; agriculture and manual (skilled and unskilled) activities are associated with higher probabilities of inadequate HIV/AIDS in Ghana. Conversely, employment in these sectors is associated with reduced likelihood of comprehensive HIV/AIDS knowledge. However, employment in the professional, technical, managerial and clerical occupations increases the probability of possessing comprehensive knowledge. The results of the effect of occupation must be taken with caution as the estimates may reflect the effect of other demographic characteristics such as education on comprehensive HIV/AIDS knowledge. Such a caution is reinforced by the correlation between educational attainment and the type of occupation.

Household wealth index is included as one of the explanatory variables as we expect that household wealth may affect household ability to access multiple sources of exposure to HIV/AIDS information. The results indicate that respondents residing in richer households (fourth and fifth quartiles) are less likely to possess inadequate knowledge of HIV/AIDS transmission modes and more likely to possess average HIV/AIDS knowledge. It is however surprising that the results reveal a negative relationship between residence in a richer household and comprehensive HIV/AIDS knowledge. This results are contrary to the findings of earlier studies (Ochako et al., 2011; Oljira, Yemane, \& Alemeyehu, 2013).

We investigate the relationship between attitudes to persons with living HIV/AIDS and the level of knowledge on HIV/AIDS transmission. The effect of the attitude variables on HIV/AIDS knowledge may be bi-causal as such attitudes may be influenced by the level of HIV/AIDS knowledge. The marginal effects indicate that respondents who reported to be willing to care for family members with HIV/AIDS are less likely to possess inadequate HIV/AIDS knowledge and increases the probability of possessing comprehensive HIV/AIDS knowledge. Equally, respondents who agreed that a teacher with HIV/AIDS should be allowed to teach are less likely to have inadequate and more likely to possess comprehensive knowledge in HIV/AIDS. Similar results are obtained for respondents report that they will buy vegetables from a vendor with HIV/AIDS. On the other hand, respondents who report to keep it secret if a family member has HIV/AIDS are less likely to possess comprehensive HIV/AIDS knowledge.

\subsection{Trends in HIV/AIDS Knowledge in Ghana}

Trends in comprehensive HIV and AIDS knowledge Survey data from 2003, 2008 and 2014 reveal an increasing trend in comprehensive HIV and AIDS knowledge from 2003 to 2008 but a decreasing trend from 2008 to 2013 among adults, in the 15-24 age bracket in Ghana. The results indicate that the percentage of adults (15 - 49 years) with comprehensive HIV and AIDS knowledge increased from 68\% to $72 \%$ between 2003 and 2008 then decreased to 59\% in 2014. These results are further illustrated in Figure 4. 


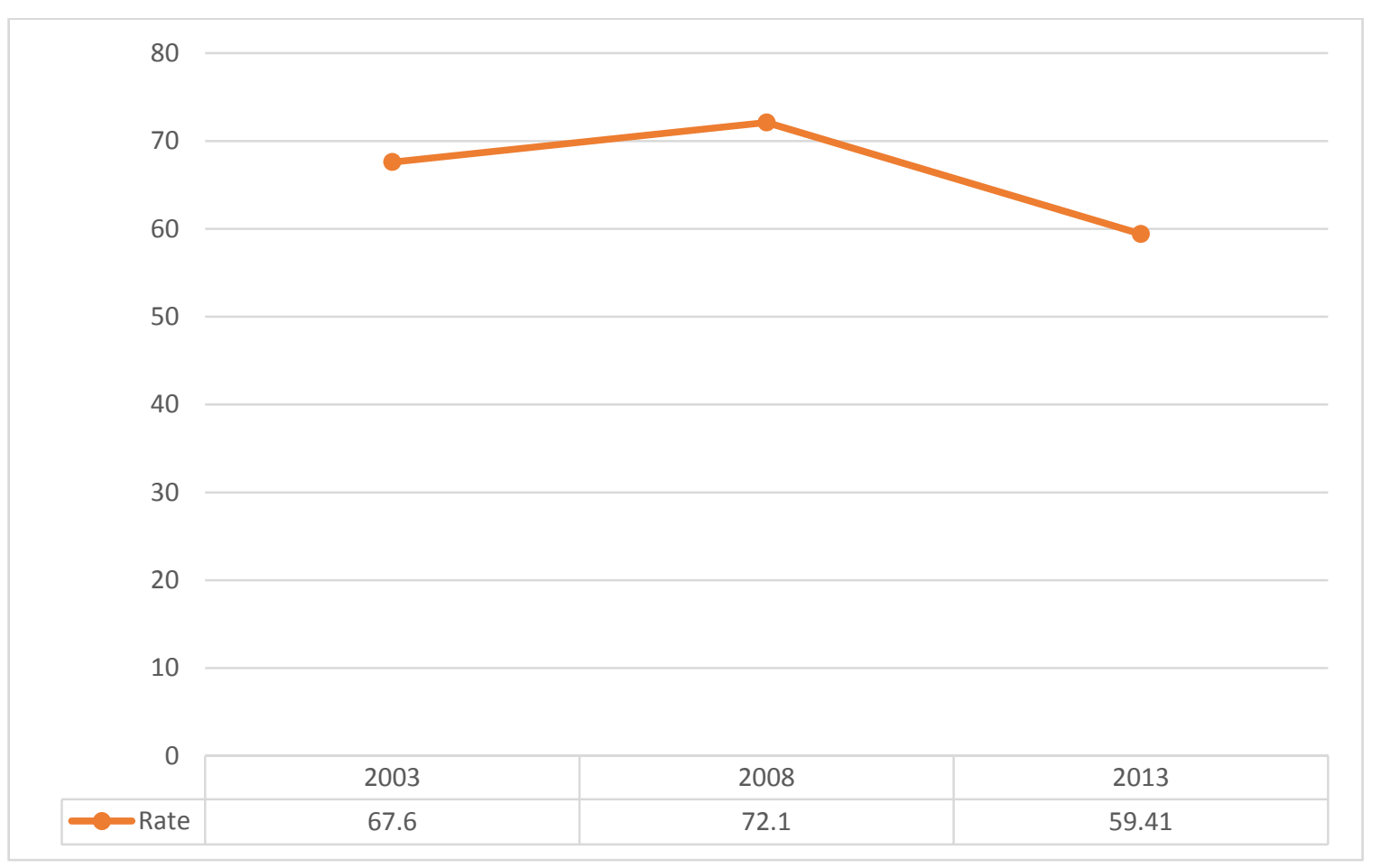

Figure 4. Rate of comprehensive HIV/AIDS Knowledge among young adults in Ghana (15-49 years), 2003-2013

\section{Discussion}

This paper examines distributions and determinants of comprehensive HIV and AIDS knowledge among adults between the ages 15 to 49 years in Ghana. The descriptive results indicate that $59 \%$ of adult women and men had comprehensive HIV and AIDS knowledge in 2014showing decrease over the 10-year period from $68 \%$ in 2003 . Although progress has been attained in terms of general awareness of HIV and AIDS which is quite high ( $98 \%$ for women and $99 \%$ for men) according to the Ghana UNGASS report for 2014, comprehensive knowledge is still way below the $90 \%$ target set by UNGASS. It is quite clear that the gap between general awareness of HIV and AIDS and comprehensive knowledge of HIV and AIDS raises concern for HIV and AIDS prevention efforts in Ghana. Accurate and high levels of comprehensive knowledge on HIV and AIDS transmission is essential if new infections can be prevented (UNGASS, 2014).

The decreasing trend in HIV and AIDS comprehensive knowledge among this adult age cohort could be attributed to inadequate provision of information during mass media campaigns. HIV campaign efforts spearheaded by the government, non-governmental and civil society organizations seemed to have lost momentum. Given that the majority of infections (72.3\%) occurred among the general low risk population, there is a need to target prevention activities to increase comprehensive knowledge of HIV and AIDS. However, workplace HIV and AIDS related activities seem to have increased comprehensive knowledge of HIV and AIDS among people who worked in the formal sectors in Ghana.

According to study findings education plays a significant role in determining one's comprehensive knowledge of HIV and AIDS. However, it also shows in the data that education status may affect one's occupation, wealth status and attitudes to PLHIVs (Rahman \& Rahman, 2007). This study found education to be a significant predictor of having comprehensive HIV and AIDS knowledge, a finding consistent with studies carried out in other countries in the sub-region (Mishra et al, 2009). A study among both women and men in slum and non-slum areas in India, showed that educated men were significantly more likely to have comprehensive knowledge of HIV/AIDS prevention methods than uneducated in non-slum areas (NJA). In Ghana, the study finds that urban dwellers were more knowledgeable compared to their rural counterparts yet this is not reflected in the wealthier cohorts. A finding that implies that richer individuals have limited comprehensive knowledge of HIV and AIDS in Ghana. A sub set of ever married and still in union respondents had less comprehensive HIV and AIDS knowledge compared to their never married counterparts. This raises a number of questions about how media campaigns on HIV and AIDS are packaged in Ghana - who is targeted and who is reached? 
The regional variations in comprehensive HIV and AIDS knowledge shown in the spatial analysis is reflective of current distribution in HIV prevalence at the regional level. For instance, the Volta region and Brong Ahafo region have the highest prevalence rate (2.7 percent) according to the 2016 HIV sentinel survey (NACP, 2017) and they are also the regions with low scores of comprehensive HIV and AIDS knowledge. The most significant change in regional prevalence is the Upper West region which increased from a prevalence rate of 1.3 percent in 2015 to 2.5 percent in 2016 (NACP, 2017). The region scored the lowest in all the three levels of comprehensive HIV and AIDS knowledge in the spatial analysis.

HIV stigma and discrimination can prevent individuals attaining adequate information about HIV and AIDS. HIV stigma and discrimination is a significant driver of new infections in Ghana. The findings from this study indicate that individuals with accepting behaviour towards PLHIV were more adequately informed and possessed adequate comprehensive knowledge of HIV and AIDS. Correct knowledge of false modes of HIV transmission is as important as correct knowledge of true modes of transmission. For example, belief that HIV is transmitted through mosquito bites can weaken motivation to adopt safe sexual behaviour. The results indicate that about $53 \%$ of respondents believed that HIV and AIDS was caused by witchcraft or supernatural means. This is a common misconception that can dissociate the causes of HIV and AIDS and key behavioural patterns such as unprotected sexual intercourse with previously infected partners (Agyemang \& Tagoe-Darko, 2012; Mbonu et al, 2009; Ahsan Ullah, 2011).

\section{Conclusion}

The level of comprehensive knowledge about HIV/AIDS has increased, but in most countries, especially in West Africa, levels remain very low although general awareness seems high. The knowledge and behaviour of most at-risk populations and other at-risk populations such as the youth play an important role in the contribution of the HIV epidemic in Ghana. Monitoring the knowledge and behaviour of the population is key to attaining Ghana's HIV and AIDS targets. Prevention programmes continue to be the main stay of the HIV response in Ghana. With a national prevalence increasing to $2.4 \%$, prevention activities must be increased as a matter of urgency to halt and reverse the HIV epidemic in the long term.

The main limitation of the paper is the difficulty in drawing conclusions with three points of cross-sectional data. However, the thematic mapping of HI/AIDS knowledge score, enables us to show the distribution of comprehensive knowledge across country. Comprehensive knowledge on HIV is the first step in the adoption of behaviours that reduce the risk of HIV transmission. The knowledge and behaviour of most at-risk populations and other at-risk populations such as the youth play an important role in the contribution of the HIV epidemic in Ghana. Monitoring the knowledge and behaviour of young people is key to attaining Ghana's goals. Combination of evidence-informed and targeted interventions in HIV programmes is the key for effective HIV prevention. However, it is also important in other settings as it can be used to ensure that pre-existing high levels of knowledge are maintained.

\section{Competing Interests Statement}

The authors declare that there are no competing or potential conflicts of interest.

\section{References}

Adedimeji, A. A. (2005). Beyond knowledge and behavior change: the social-structural context of HIV/AIDS risk perceptions and protective behavior among young urban slum inhabitants in Nigeria. Boston, MA: Department of Population and International Health Harvard School of Public Health.

Agyemang, S., Buor, D., \& Tagoe-Darko, E. (2012). The extent of knowledge about HIV/AIDS among young people in the Ejura-Sekyedumase district of Ghana. Journal of AIDS and HIV Research, 4(11), 241-247. https://doi.org/10.5897/JAHR12.023

Ahsan Ullah, A. K. M. (2011). HIV/AIDS-related stigma and discrimination: A study of health care providers in Bangladesh. Journal of the International Association of Physicians in AIDS Care, 10(2), 97-104. https://doi.org/10.1177/1545109710381926

Bivand, R., Pebesma, E. J., \& Gómez-Rubio, V. (2008). Applied spatial data analysis with R (Vol. Use R!). New York: Springer.

Brown, L., Macintyre, K., \& Trujillo, L. (2003). Interventions to reduce HIV/AIDS stigma: what have we learned? AIDS education and prevention, 15(1), 49-69. https://doi.org/10.1521/aeap.15.1.49.23844

Ghana Statistical Service. (2003). Ghana Demographic and Health Survey 2003. Accra, Ghana. 
Ghana Statistical Service. (2008). Ghana Demographic and Health Survey 2008. Accra, Ghana.

Ghana Statistical Service. (2014). Ghana Demographic and Health Survey 2014. Accra, Ghana.

Hausman, J., \& McFadden, D. (1984). Specification tests for the multinomial logit model. Econometrica: Journal of the Econometric Society, 1219-1240. https://doi.org/10.2307/1910997

Jha, P. K., Narayan, P., Nair, S., Ganju, D., Sahu, D., \& Pandey, A. (2015). An assessment of comprehensive knowledge of HIV/AIDS among slum and non-slum populations in Delhi, India. Open Journal of Preventive Medicine, 5(06), 259. https://doi.org/10.4236/ojpm.2015.56029

Mbonu, N. C., van den Borne, B., \& De Vries, N. K. (2009). Stigma of people with HIV/AIDS in Sub Saharan Africa: a literature review. Journal of tropical medicine, 2009. https://doi.org/10.1155/2009/145891

Mishra, V., Agrawal, P., Alva, S., Gu, Y., \& Wang, S. (2009). Changes in HIV-related knowledge and behaviors in sub-Saharan Africa. DHS Comparative Reports No. 24. Calverton, Maryland, USA: ICF Macro.

National AIDS/STI Control Program (NACP) 2017.

Nketiah-Amponsah, E., \& Afful-Mensah, G. (2013). A review of HIV/AIDS awareness and knowledge of preventive methods in Ghana. African journal of reproductive health, 17(4), 69-82.

Ochako, R., Ulwodi, D., Njagi, P., Kimetu, S., \& Onyango, A. (2011). Trends and determinants of Comprehensive HIV and AIDS knowledge among urban young women in Kenya. AIDS Research and Therapy, 8(1), 11. https://doi.org/10.1186/1742-6405-8-11

Odu, B. K., \& Akanle, F. F. (2008). Knowledge of HIV/AIDS and sexual behaviour among the youths in South West Nigeria. International Journal of Tropical Medicine, 3(4), 79-84.

Oljira, L., Berhane, Y., \& Worku, A. (2013). Assessment of comprehensive HIV/AIDS knowledge level among in-school adolescents in eastern Ethiopia. Journal of the International AIDS Society, 16(1). https://doi.org/10.7448/IAS.16.1.17349

Rahman, M. S., \& Rahman, M. L. (2007). Media and education play a tremendous role in mounting AIDS awareness among married couples in Bangladesh. AIDS Research and Therapy, 4(1), 10. https://doi.org/10.1186/1742-6405-4-10

Sweat, M. D., \& Denison, J. A. (1995). Reducing HIV incidence in developing countries with structural and environmental interventions. Aids, 9, S251-7.

United Nations General Assembly Special Session (UNGASS) 2014: Country Aids Response Progress Report Ghana

Wang, W., Alva, S., \& Wang, S. (2012). HIV-related knowledge and behaviors among people living with HIV in eight high HIV prevalence countries in sub-Saharan Africa. DHS Analytical Studies No. 29. Calverton, Maryland, USA: ICF International.

\section{Notes}

Note 1. Ghana - Modes of HIV Transmission in West Africa Study, 2014.

Note 2. http://www.diva-gis.org/datadown 2- Accessed 02 May 2017.

Note 3. http://www.gadm.org/country 2 - Accessed 02 May 2017.

\section{Copyrights}

Copyright for this article is retained by the author(s), with first publication rights granted to the journal.

This is an open-access article distributed under the terms and conditions of the Creative Commons Attribution license (http://creativecommons.org/licenses/by/4.0/). 